\title{
Intramolecular Cyclohexadienone Annulations of Fischer Carbene Complexes: Model Studies for the Synthesis of Phomactins
}

\author{
Jie Huang, Huan Wang, Chunrui Wu, and William D. Wulff ${ }^{*}$ \\ Department of Chemistry, Michigan State University, East Lansing, MI 48824
}

\begin{abstract}
The intramolecular cyclohexadienone annulation of chromium carbene complexes is examined as a method to provide general access to the Phomactin family of natural products. The importance of the stereochemistry of the carbene complex and the number of carbons in the tether connecting the carbene complex and the alkyne are probed. Additionally, the degree of the 1,4-asymmetric induction is examined.
\end{abstract}

Since the discovery ${ }^{1}$ of the phomactins in the early to mid 1990's, their unusual carbon skeleton combined with attractive bioactivity as PAF antagonists has prompted much interest among synthetic organic chemists. ${ }^{2,3,4}$ The structures of the phomactins share a common bicyclo [9.3.1] pentadecane ring system featuring a highly substituted cyclohexane bearing a quarternary center and a 12-membered macrocycle (Figure 1).

The phomactins and members of the taxol family share a common biosynthetic pathway (Figure 2). ${ }^{2,5}$ Cyclization of geranylgeranyl diphosphate gives rise to the verticillenyl carbocation $\mathbf{1 3}$ which can lead to verticilllene $\mathbf{1 2}$ by simple proton loss or to taxadiene $\mathbf{1 1}$ via an intramolecular proton transfer and subsequent intramolecular cyclization. Alternatively, it has been shown that cation 13 is the precursor to phomactatriene 14 via a series of 1,2-hydrogen and 1,2-methyl shifts. ${ }^{5 a}$ Phomactatriene $\mathbf{1 4}$ is also a natural product and has been isolated from Phoma sp. and its stereochemistry recently corrected. ${ }^{5 \mathrm{~b}}$ It has been suggested by Pattenden that the last common intermediate to all the phomactins in the biosynthesis is the keto expoxide $\mathbf{1 5}$ which results from oxidations of phomactatriene. ${ }^{2}$

We envisioned that the bicyclic cyclohexadienone $\mathbf{1 6}$ could also serve as a common intermediate for the synthesis of all of the phomactins in much the same way that the epoxy ketone $\mathbf{1 5}$ has been proposed to be the biosynthetic precursor to all of the phomactins. ${ }^{2}$ All of the previous synthetic approaches ${ }^{3}$ and total syntheses ${ }^{4}$ of the phomactins have constructed the six-membered ring before the macrocycle is closed. Closure of the macrocycle has been effected by a number of different tactical methods including NHK coupling, $4 \mathrm{~b}, 4 \mathrm{~d}-\mathrm{e}, 3 \mathrm{i}$ Suzuki coupling, ${ }^{4 c, 3 e}$ Stille coupling, $3 \mathrm{k}$ sulfone coupling to an allyic halide, ${ }^{4 a}, 3 \mathrm{n}$ and oxa[3+3] cycloaddition. ${ }^{3 \mathrm{~m}, 3 \mathrm{q}}$ Our retrosynthesis for the phomactins involves the intramolecular cyclohexadienone annulation of the carbene complex 17 (Scheme 1). Thermolysis of 17 would be anticipated to lead to the formation of 6 membered and 12 membered ring in the same event.

The benzannulation reaction of $\alpha, \beta$-unsaturated carbene complexes with alkynes is one of the most important methods for the synthesis of phenols (Scheme 2). This reaction was discovered 
in 1975 by Dötz and since that time ${ }^{6}$ the reaction has been extensively studied and widely applied in organic synthesis. ${ }^{7}$ We reported the cyclohexadienone annulation in 1985 which involves the reaction of carbene complexes of the type 18 where both substituents of the $\beta$ carbon are non-hydrogen. ${ }^{8}$ The reaction of such complexes with alkynes is general and allows for rapid entry to cyclohexadienones bearing a quaternary carbon. ${ }^{7}$ The intramolecular variant of the benzannulation reaction has been known ${ }^{9,10}$ for quite some time and has been utilized in the total synthesis of deoxyfrenolicin, $9 \mathrm{~b}, \mathrm{c}, \mathrm{g}$ angelicin, $, 9 \mathrm{~d}, \mathrm{e}$ sphondin, $9 \mathrm{e}$ and arnebinol. $9 \mathrm{~h}$ The intramolecular version of the cyclohexadienone annulation is unknown and is the subject of the present work.

The retrosynthesis of the phomactins shown in Scheme 1 requires the carbene complex 17 and thus as model systems we chose to prepare a family of carbene complexes of the type $\mathbf{2 2}$ (Scheme 2) in which the alkyne is tethered to the $\beta$-carbon of the alkenyl substituent of the carbene complex. It was anticipated that it would be important not only to include complexes of the type $\mathbf{2 2}$ with different tether lengths in the initial screen of the intramolecular cyclohexadienone annulation but also to include complexes with both cis and trans doublebonds in the carbene complex. It is known ${ }^{11}$ that $\beta, \beta$-disubstituted alkenyl carbene complexes are configurationally stable under the conditions of the cyclohexadienone annulation and thus it is certainly possible that cis and trans isomers of $\mathbf{2 2}$ could behave differently during the intramolecular process involving the carbene complex and the tethered alkyne unit. The Eisomer of complex 22 was prepared from the E-vinyl iodide precursor $E$-21 via the standard Fischer method involving the addition of the vinyllithium derived from $E-21$ with chromium hexacarbonyl followed by methylation. The Z-isomer of $\mathbf{2 2}$ was prepared from the corresponding Z-isomer of the vinyl iodide $\mathbf{2 1}$ (not shown) and the details can be found in the supporting information. More rapid entry to these carbene complexes is possible via the aldol reaction ${ }^{12}$ of the methyl carbene complex $\mathbf{2 3}$ with the ketone $\mathbf{2 4}$ (Scheme 2), unfortunately, this route produces a mixture of the Z- and E-isomers of $\mathbf{2 2}$ which proved to be inseparable.

The intramolecular cyclohexadienone annulation of carbene complex 22 was examined with complexes of four different tether lengths and the results are presented in Table 1. The yield of the desired bicyclic cyclohexadienone 25 increases with increasing tether length until $n=$ 10 and then appears to level off. The phomactins have nine carbons in the larger bridge and the results in Table 1 are encouraging since reasonable yields of the cyclized product $\mathbf{2 5}$ can be realized with both eight and ten methylene tethers. However, none of the desired cyclized product $\mathbf{2 5}$ is seen with the complex 22a with six methylene spacers. In this case, depending on solvent, up to a $46 \%$ yield of the dimeric cyclohexadienone $\mathbf{2 6}$ was observed as a 1.1:1.0 mixture of diastereomers along with smaller amounts of the corresponding trimeric product (not shown). In acetonitrile the ratio of the dimers was formed in a 1.8:1.0 ratio and the stereochemistry of the major diastereomer was confirmed by an X-ray diffraction study. This study of intramolecular cyclohexadienone annulation of complexes 22 also clearly reveals that the stereochemistry of the double-bond of the carbene complex is very important. The Z-isomer of complex $\mathbf{2 2}$ gives a $15 \%$ yield of $\mathbf{2 5}$, whereas, the E-isomer gives a $43 \%$ yield (entries 7 vs. 9). Interestingly, a 79:21 mixture of E:Z isomers of 22c was prepared by the aldol reaction indicated in Scheme 2 and the thermolysis of this mixture gave a 37\% yield of $\mathbf{2 5}$ (Table 1, entry 8). Based on the data for the pure E-and Z-isomers (entries 7 and 9), the expected yield would have been $35 \%$.

We have previously shown that high levels of 1,4-asymmetric induction could be achieved in the intermolecular cyclohexadienone annulations with propargyl ethers. ${ }^{11}$ For example, the reaction of the carbene complex $\mathbf{2 7}$ with the trityl propargyl ether $\mathbf{2 8}$ are stereospecific (Scheme 3 ). It is thought that the origins of this stereoselectivity derives from a stereoelectronic preference for the propargyl oxygen to be anti to the chromium in the $\eta^{1}, \eta^{3}$-vinyl carbene complexed intermediate which can exist as the two diastereomeric forms $\mathbf{3 1}$ and $\mathbf{3 3}$ when 
E-27 was cylized. Of the two, intermediate $\mathbf{3 1}$ is expected to be the more stable for steric reasons. Insertion of a $\mathrm{CO}$ ligand gives the vinyl ketene complex $\mathbf{3 2}$ and then an electrocyclic ring closure with upward movement of the methyl would be expected to avoid close contacts of the methyl group with the chromium and its CO ligands to provide $\mathbf{2 9}$ as the major product. Thus cyclization of Z-27 gave the opposite selectivity favoring formation of $\mathbf{3 0}$.

A series of carbene complexes $\mathbf{3 4}$ were prepared which had ten carbons in the tether and which had a variety of propargyl substituents to determine the extent of 1,4-asymmetric induction in the intramolecular cyclohexadieneone annulation (Table 2). It was no surprise that carbon substituents gave 1:1 mixtures of isomers since this had also been found to be the case for intermolecular benzannulations. ${ }^{13}$ However, oxygen substiutents were found to give high selectivity in the intermolecular benzannuation ${ }^{13}$ and cyclohexadienone annulations. ${ }^{11}$ Clearly, from the data in Table 2, the intramolecularity of the reaction leads to very low stereoselectivities with propargyl oxygen substituents. This is not necessarily a surprise given the geometrical constraints that can be associated with intramolecular processes. The best selectivity of 3:1 was observed with a siloxy group and this is consistent with the increased electron releasing ability of a siloxy group. ${ }^{13,14}$ This result is significant since it provides for an asymmetric entry to the phomactins via carbene complex 17 . The introduction of the proper configuration at the alcohol carbon in $\mathbf{1 7}$ would allow for 1,4-asymmetric induction in the $\mathbf{1 6}$ and thus to asymmetric syntheses of the phomactins.

The success of these model systems is quite encouraging for the development of an approach to the phomactins involving a double cyclization of an alkyne tethered carbene complex. Thermolysis of these complexes generates macrocyclic embedded cyclohexadienones and work directed to the synthesis of the phomactins utilizing this process will be reported in due course.

\section{Supplementary Material}

Refer to Web version on PubMed Central for supplementary material.

\section{Acknowledgment}

This work was supported by a grant from the NIH (GM 33589).

\section{References}

1. (a) Sugano M, Sato A, Iijima Y, Oshima T, Furuya K, Kuwano H, Hata T, Hanzawa H. J. Am. Chem. Soc 1991;113:5463. (b) Chu M, Patel MG, Gullo VP, Truumees I, Puar MS, McPhail AT. J. Org. Chem 1992;57:5817. (c) Chu M, Truumees I, Gunnarsson I, Bishop WR, Kreutner W, Horan AC, Patel MG, Gullo VP, Puar MS. J. Antibiot 1993;46:554. [PubMed: 8500998] (d) Sugano M, Sato A, Iijima T, Furuya K, Haruyama H, Yoda K, Hata T. J.Org.Chem 1994;59:564. (e) Sugano M, Sato A, Ijima T, Furuya K, Kuwano H, Hata T. J. Antibiot 1995;48:1188. [PubMed: 7490234] (f) Koyama K, Ishino M, Takatori K, Sugita T, Kinoshita K, Takahashi K. Tetrahedron Lett 2004;45:6947.

2. For a review of the phomactins, see: Goldring WPD, Pattenden G. Acc. Chem. Res 2006;39:354. [PubMed: 16700534]

3. For studies directed at the synthesis of phomactins, see: (a) Foote KM, Hayes CJ, Pattenden G. Tetrahedron Lett 1996;37:275. (b) Chen D, Wang J, Totah NI. J. Org. Chem 1999;64:1776. [PubMed: 11674261] (c) Seth PP, Totah NI. J. Org. Chem 1999;64:8750. (d) Seth PP, Totah NI. Org. Lett 2000;2:2507. [PubMed: 10956533] (e) Kallan NC, Halcomb RL. Org. Lett 2000;2:2687. [PubMed: 10990428] (f) Chemler SR, Danishefsky SJ. Org. Lett 2000;2:2695. [PubMed: 10990430] (g) Seth PP, Chen D, Wang J, Gao X, Totah NI. Org. Lett 2000;56:10185. (h) Foote K, John M, Pattenden G. Synlett 2001:365. (i) Mi B, Maleczka R. Org. Lett 2001;3:1491. [PubMed: 11388849] (j) Chemler SR, Iserloh U, Danishefsky SJ. Org. Lett 2001;3:2949. [PubMed: 11554815] (k) Houghton T, Choi S, Rawal VH. Org. Lett 2001;3:3615. [PubMed: 11700095] (1) Mohr PJ, Halcomb RL. Org. Lett 
2002;4:2413. [PubMed: 12098260] (m) Cole K, Hsung RP. Org. Lett 2003;5:4843. [PubMed: 14653688] (n) Balnaves AS, McGowan G, Shapland PDP, Thomas EJ. Tetrahedron Lett 2003;44:2713. (o) Foote KM, Hayes CJ, John MP, Pattenden G. Org. Biomol. Chem 2003;1:3917. [PubMed: 14664383] (p) Cheing JWC, Goldring WPD, Pattenden G. Chem. Commun 2003:2788. (q) Cole KP, Hsung RP. Chem. Commun 2005:5784. (q) Ryu K, Cho Y-S, Jung S-I, Cho C-G. Org. Lett 2006;8:3343. [PubMed: 16836401]

4. For the total syntheses of phomactins, see: (a) Miyaoka H, Saka Y, Miura S, Yamada Y. Tetrahedron Lett 1996;37:7107.Phomactin A (b) Goldring WPD, Pattenden G. Chem. Commun 2002:1736. (c) Mohr PJ, Halcomb RL. J. Am. Chem. Soc 2003;125:1712. [PubMed: 12580592] (d) Diaper CM, Goldring WPD, Pattenden G. Org. Biomol. Chem 2003;1:3949. [PubMed: 14664384]Phomactin G (e) Goldring WPD, Pattenden G. Org. Biomol. Chem 2004;2:466. [PubMed: 14770224]

5. (a) Tokiwano T, Endo T, Tsukagoshi T, Goto H, Fukushi E, Oikawa H. Org. Biomol. Chem 2005;3:2713. [PubMed: 16032349] (b) Tokiwano T, Fukushi E, Endo T, Oikawa H. Chem. Commun 2004:1324.

6. Dötz KH. Angew. Chem. Int. Ed. Engl 1975;14:644.

7. For reviews on the benzannulation and cyclohexadienone annulations, see: (a) WulffWDAbelEWStoneRGAWilkinsonGComprehensive Organometallic Chemistry II1995Vol. 12Pergemon Press469547 (b) Minatti A, Dötz KH. Top. Organomet. Chem 2004;13:123. (c) Waters ML, Wulff WD. Org. React. in press

8. Tang PC, Wulff WD. J. Am. Chem. Soc 1984;106:1132.

9. For reactions tethered through the oxygen on the carbene carbon, see: (a) Semmelhack MF, Bozell JJ. Tetrahedron Lett 1982;23:2931. (b) Semmelhack MF, Bozell JJ, Sato T, Wulff W, Spiess EJ, Zask A. J. Am. Chem. Soc 1982;104:5850. (c) Semmelhack MF, Bozell JJ, Keller L, Sato T, Spiess EJ, Wulff W, Zask A. Tetrahedron 1985;41:5803. (d) Peterson GA, Kunng F-A, McCallum JS, Wulff WD. Tetrahedron Lett 1987;28:1381. (e) Wulff WD, McCallum JS, Kunng F-A. J. Am. Chem. Soc 1988;110:7419. (f) Balzer BL, Cazanoue M, Finn MG. J. Am. Chem. Soc 1992;114:8735. (g) Gross MF, Finn MG. J. Am. Chem. Soc 1994;116:10921. (h) Watanabe M, Tanaka K, Saikawa Y, Nakata M. Tetrahedron Lett 2007;48:203.

10. For reactions tethered through the alkenyl group on the carbene carbon, see: (a) Wang H, Wulff WD. J. Am. Chem. Soc 1998;120:10573. (b) Dötz KH, Gerhardt A. J. Organomet. Chem 1999;578:223. (c) Wang H, Wulff WD, Rheingold AL. J. Am. Chem. Soc 2000;122:9862. (d) Dötz KH, Mittenzwey S. Eur. J. Org. Chem 2002:39. (e) Wang H, Huang J, Wulff WD, Rheingold AL. J. Am. Chem. Soc 2003;125:8980. [PubMed: 15369331] (f) Gopalsamuthiram V, Wulff WD. J. Am. Chem. Soc 2004;126:13936. [PubMed: 15506750]

11. Hsung RP, Quinn JF, Weisenberg BA, Wulff WD, Yap GPA, Rheingold AL. Chem. Commun 1997:615.

12. Wang H, Hsung RP, Wulff WD. Tetrahedron Lett 1998;39:1849.

13. Hsung RP, Wulff WD, Rheingold AL. J. Am. Chem. Soc 1994;116:6449.

14. Lorsbach BA, Prock A, Giering WP. Organometallics 1995;14:1694. 


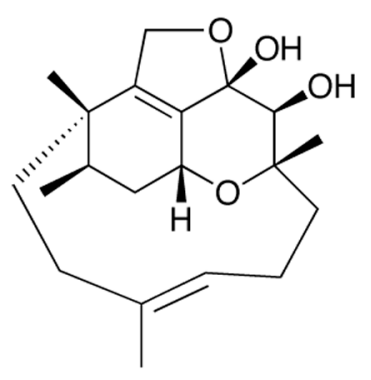

Phomactin A 1

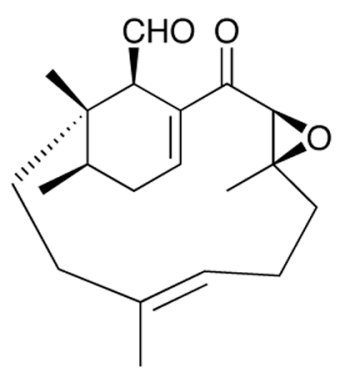

Phomactin C 5

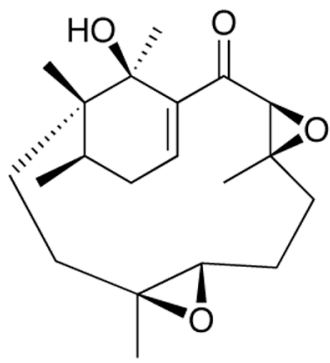

Phomactin F 8

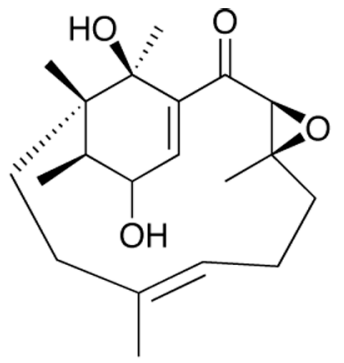

Phomactin B $2 \alpha-\mathrm{OH}$ Phomactin B1 $3 \beta-\mathrm{OH}$

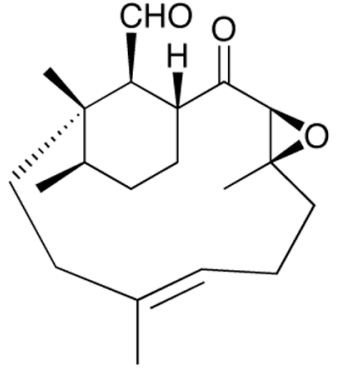

Phomactin D 6

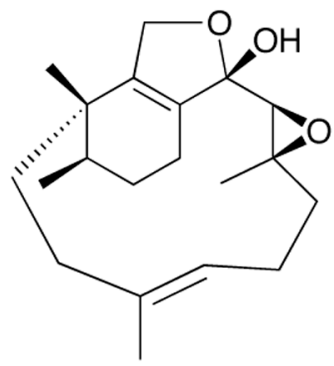

Phomactin G 9

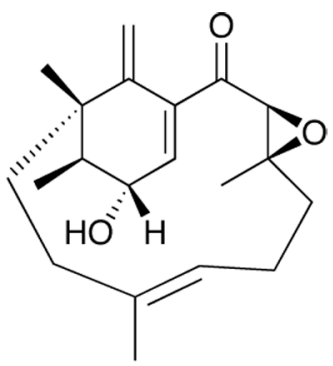

Phomactin B2 4

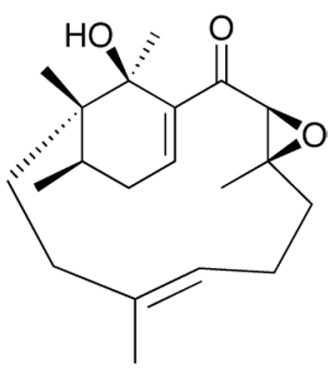

Phomactin E 7

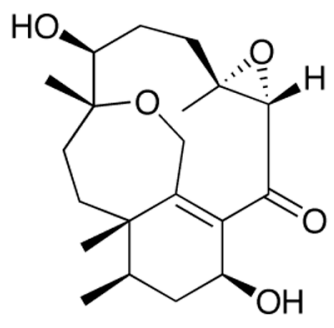

Phomactin $\mathrm{H} 10$

Figure 1.

The Phomactin Family of Natural Products. 


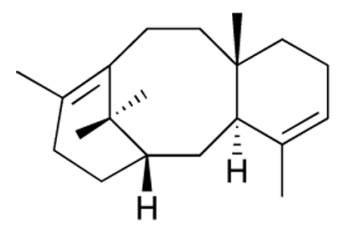

Taxadiene 11

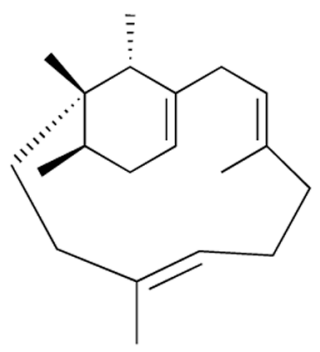

Sch 4902614

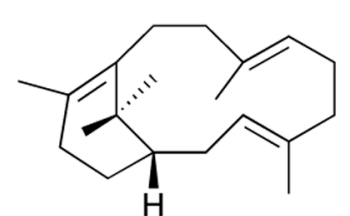

Verticillene 12

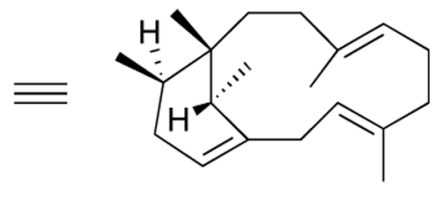

Sch 4902614

Phomactatriene

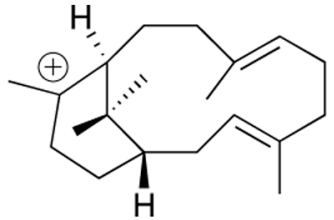

13

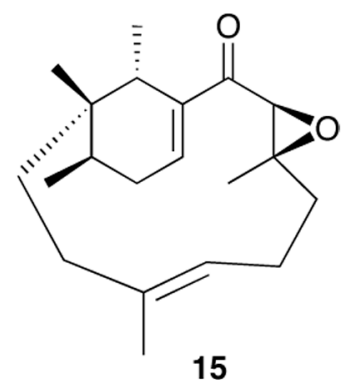

Phomactatriene

Figure 2.

Biosynthesis of Phomactins and Taxol. 

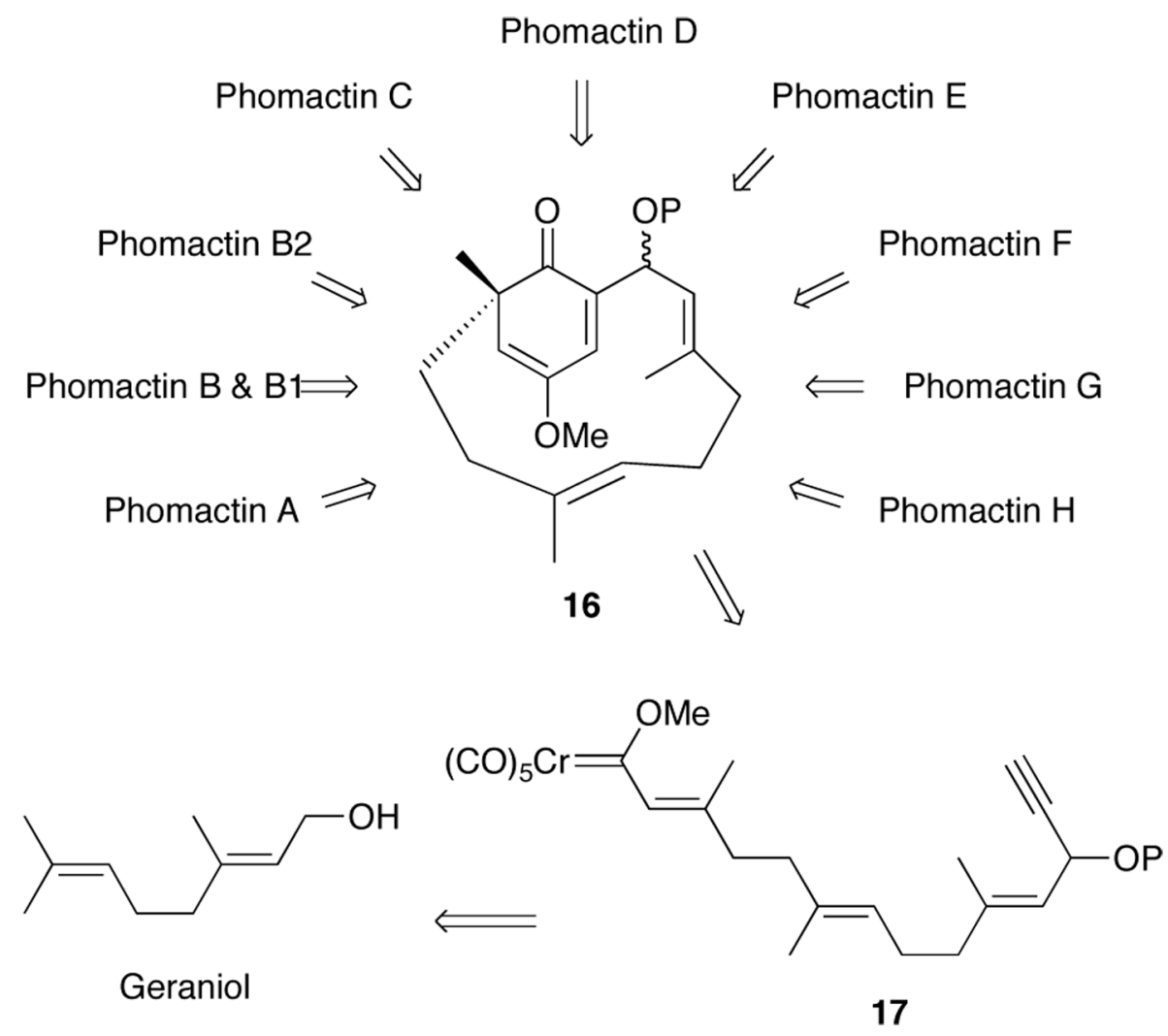

Scheme 1.

Retrosynthetic Analysis for the Phomactins 


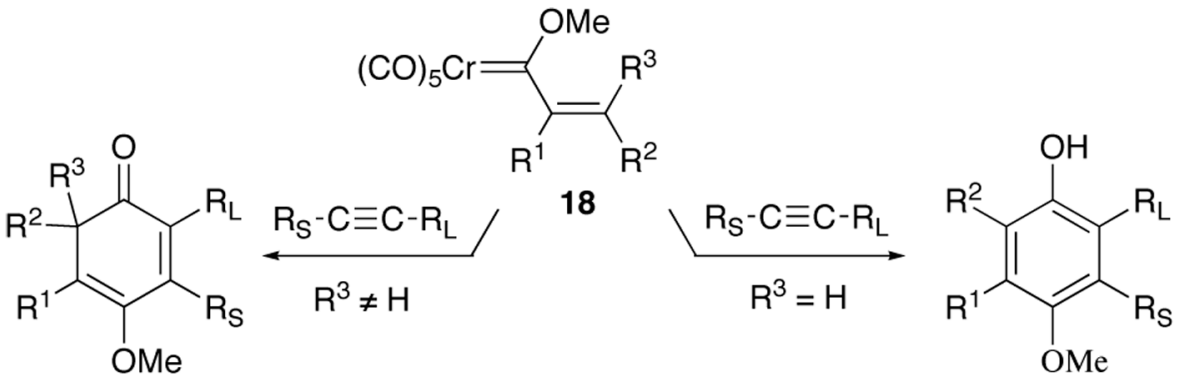

19

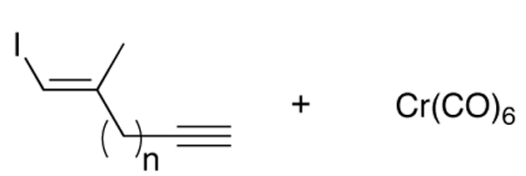

E-21<smiles>COC(C)=C(C)OC</smiles>

23

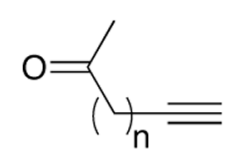

24

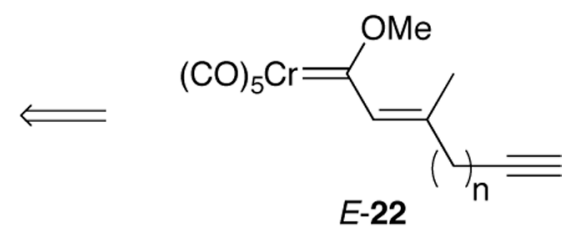

$\Longleftarrow$

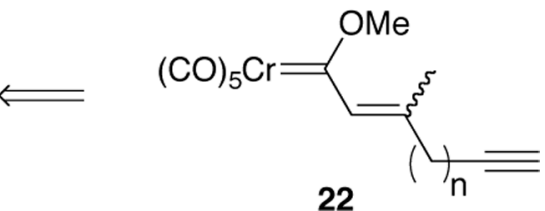

Scheme 2.

Cyclohexadienone Annulation and Benzannulation 
<smiles>CC/C(C)=C/C(OC)=C(C(C)(C)C)C(C)(C)C</smiles>

E-27

Z-27

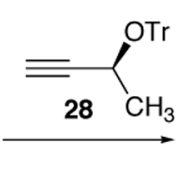

$\stackrel{\mathrm{CH}_{3}}{\longrightarrow}$

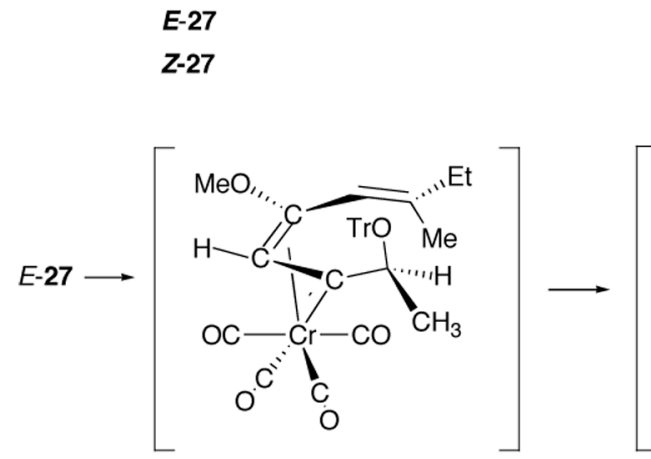

31
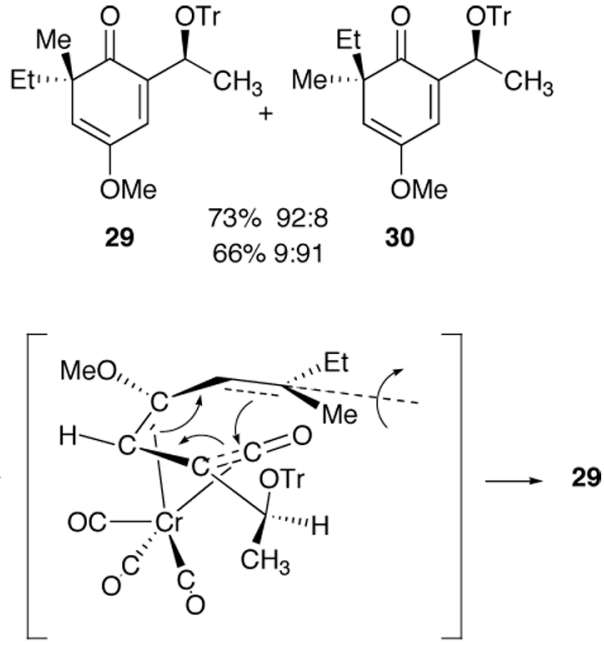

32

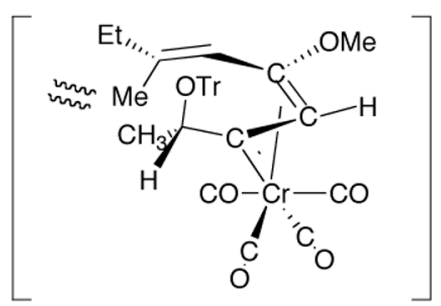

33

Scheme 3.

1,4-Asymmetric Induction in Intermolecular Cyclohexadienone Annulation 


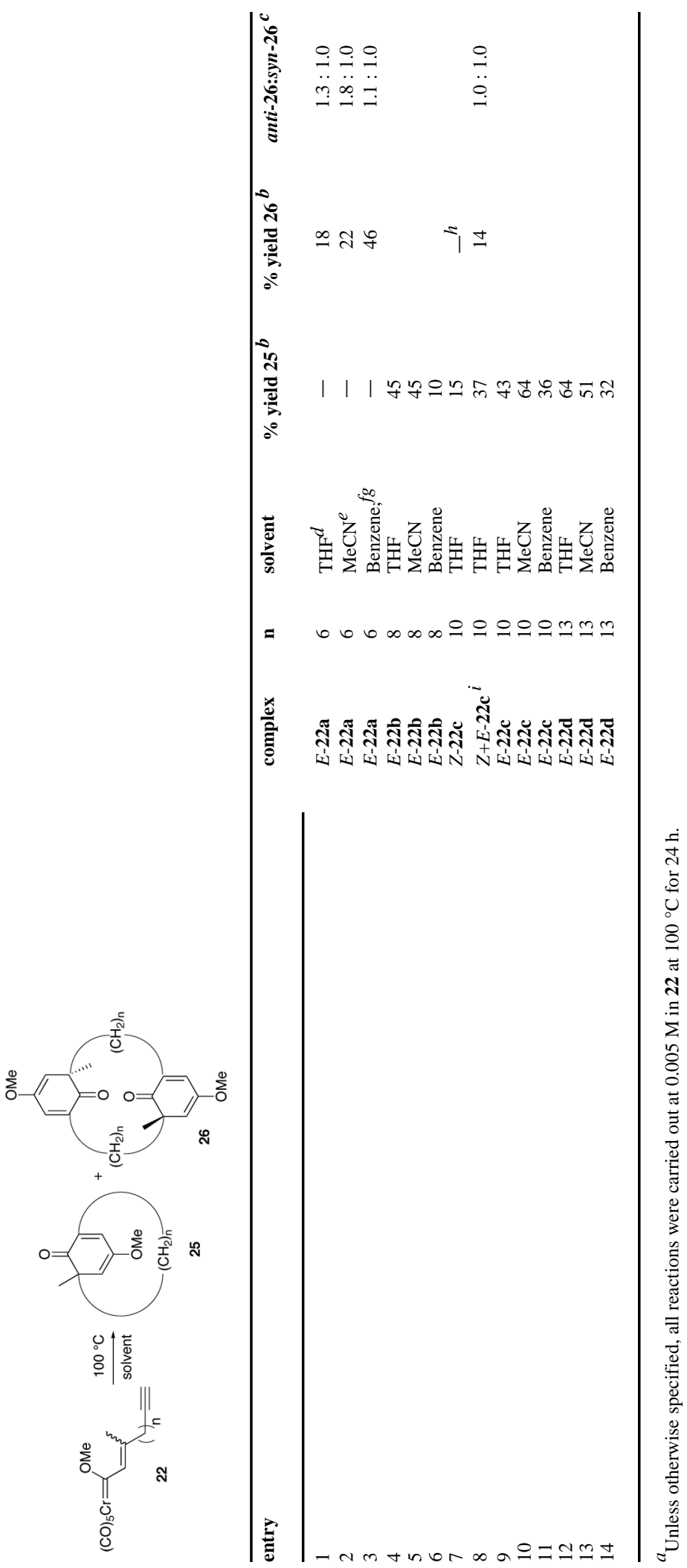

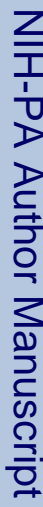

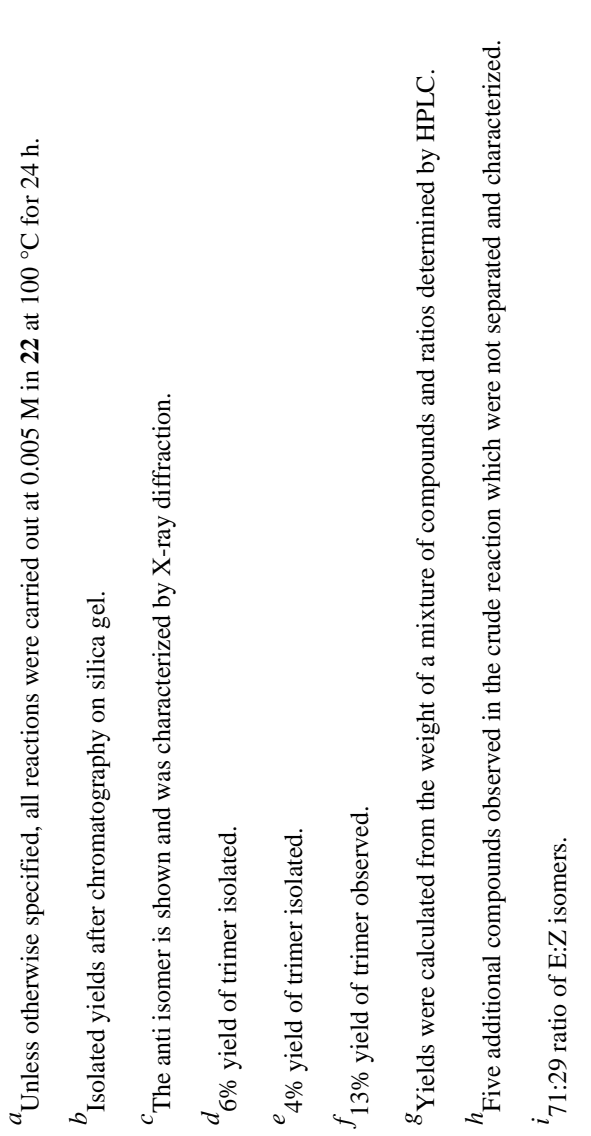

Org Lett. Author manuscript; available in PMC 2008 September 4. 


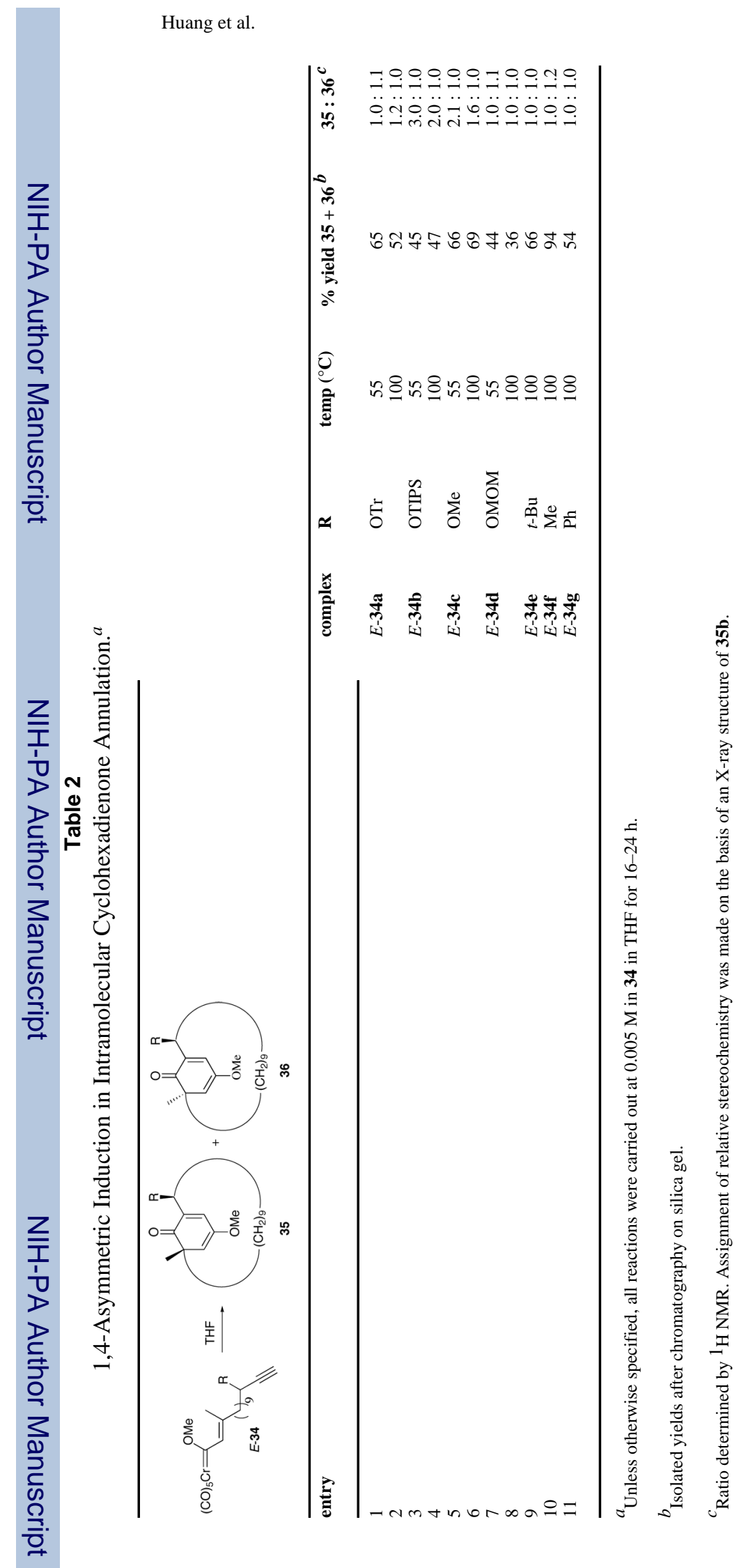

Page 11 